\title{
The Reliability of Self-administration of Dapsone by Leprosy Patients in Burma
}

\author{
KATHLEEN J. HAGAN AND S. E. SMITH \\ Department of Pharmacology, St Thomas's Hospital Medical School, \\ London SE1 7EH, England \\ KIN MA GYI, MAUNG MAUNG LWIN, YI YI MYAING \\ AND KHIN MAW OO \\ Department of Pharmacology, Institute of Medicine 2, Rangoon, Burma
}

TIN SHWE

Leprosy Hospital, Htauk Kyant, Rangoon, Burma

and
KHIN MAUNG TIN, KHIN NYUNT THAN, THIDA HLA AND WIN WIN KYWE

Department of Pharmacology, Institute of Medicine, Mandalay, Burma

\begin{abstract}
A study of urinary dapsone/creatinine $(\mathrm{D} / \mathrm{C})$ concentration ratios has been performed on 852 leprosy patients in the Rangoon and Mandalay regions of Burma. The results show that, by comparison with in-patients who are assumed to be compliant with their therapy, hospital out-patients and urban and rural clinic patients had overall compliance rates of only $74 \%$ and $24 \%$ respectively. In each group, substantial numbers of patients were identified who had taken no dapsone (DDS) tablets whatsoever.

The findings are in line with similar studies performed in other countries and they indicate an urgent need to reassess the existing programme of treatment supervision particularly in the urban and rural clinic environments.
\end{abstract}

\section{Introduction}

Compliance with DDS therapy may be monitored by a quantitative test in which DDS and its diazotizable metabolites, and creatinine concentrations, are determined on single urine samples (Ellard et al., 1974a). The DDS/creatinine (D/C) concentration ratios measured on urine samples from patients receiving 
supervised administration of DDS are compared with the urinary D/C concentration ratios determined from patients who are relied upon to selfadminister their DDS. An estimation may then be made of the percentage of prescribed DDS therapy taken by the unsupervised patients (Ellard et al., 1974b).

Compliance with DDS therapy has been studied in populations of leprosy patients in Africa, (Ellard et al., 1974b; Low and Pearson, 1974; Huikeshoven et al., 1976) and India (Balakrishnan, 1977; Naik and Ganapati, 1977). The results show disappointingly low levels of compliance among out-patients.

This paper assesses, in a similar manner to previous authors, compliance with DDS therapy by leprosy patients in two regions of Burma-Mandalay and Rangoon. The degree of supervision with therapy varies between groups of patients in these areas. A small proportion of patients who are resident in leprosy hospitals receive full supervision of their medication, while other patients regularly attend out-patient clinics but are relied upon to administer their own medication. The majority of the Burmese patients studied live in rural areas and receive treatment through a system of drug distribution by leprosy health workers. The successful mass treatment of leprosy is therefore largely dependent on the regularity of patients to self-administer their medication and on the system of drug distribution. Some of the present findings have been the subject of a previous report (Kin Ma Gyi et al., 1978) and are reassessed together with further findings obtained in different parts of Burma, which are published for the first time.

\section{Methods}

\section{PATIENTS}

All leprosy patients were on a 6 days/week regimen of either $12.5 \mathrm{mg}$, $25 \mathrm{mg}, 50 \mathrm{mg}, 75 \mathrm{mg}$ or $100 \mathrm{mg}$ DDS with the exception of one patient taking $200 \mathrm{mg}$. Urine samples were collected from a total of 852 patients in Mandalay and Rangoon. The patients consisted of the following groups:

(a) Leprosy hospital patients: in Mandalay residents receiving either $100 \mathrm{mg}$ or $50 \mathrm{mg}$ DDS, and in Htauk Kyant, Rangoon, residents receiving $50 \mathrm{mg}$ DDS, each provided a urine sample $24 \mathrm{~h}$ after ingestion of DDS therapy. Hereinafter these patients are ref erred to as IN-PATIENTS.

(b) Hospital out-patients: urine samples were collected from patients at their weekly visit to the Special Skin Clinic at Mandalay General Hospital and these patients were prescribed either $12.5 \mathrm{mg}, 25 \mathrm{mg}, 50 \mathrm{mg}$ or $100 \mathrm{mg}$ DDS. Urine samples were provided also by patients attending their weekly visit to the Htauk-Kyant out-patient clinic in Rangoon and those patients attending Rangoon General Hospital out-patient clinic. The Rangoon out-patients were prescribed $50 \mathrm{mg}$ DDS. Hereinafter these patients are referred to as OUTPATIENTS.

(c) Urban and rural clinic patients: in Mandalay, urine samples were provided by patients prescribed either $25 \mathrm{mg}, 50 \mathrm{mg}, 75 \mathrm{mg}$ or $100 \mathrm{mg}$ DDS. These patients live in the townships of Madaya, Patheingyi and Amarapura and Maymyo Town. In Rangoon, urine samples were provided by patients from 
Htauk Kyant village, prescribed $50 \mathrm{mg}$ DDS, and patients from Taik Kyi village and the Hmawbi and Hlegu areas, all prescribed $100 \mathrm{mg}$ DDS. Leprosy workers collected urine samples from the urban and rural clinic patients at surprise visits by the worker to each village or town. Hereinafter these patients are referred to as URBAN AND RURAL CLINIC PATIENTS.

Areas from which patient urine samples were obtained are identified by map references, indicated in Fig. 1.

All urine samples from the Rangoon patients were collected and preserved in 0.5 volumes of $2 \mathrm{~N} \mathrm{HCl}$. Urine samples from the Mandalay patients were not acidified but were refrigerated until determinations could be carried out. Ten volunteers from the staff of the Htauk Kyant Leprosarium, Rangoon, provided urine samples for control determinations.

\section{CREATININE AND DDS DETERMINATIONS}

Creatinine was determined by the alkaline picrate method (Ellard et al., 1974a). DDS, as total diazotizable compounds, was determined by modifications of the Bratton and Marshall (1939) procedure. In Rangoon, the modification carried out was as described by Ellard et al. (1974a); in Mandalay, as recently described by Hagan and Smith (1979).

\section{EXCLUSION OF DATA}

D/C concentration ratios of 53 patients were excluded from this study, leaving 799 out of the original 852 results. The reason for such exclusion was that these samples had unusually high $\mathrm{D} / \mathrm{C}$ concentration ratios. Some had creatinine levels of zero, suggesting that the samples were not urine at all. Others, with measurable creatinine concentrations, had grossly high DDS concentrations, indicating either that the samples were contaminated or that the patients were taking sulphonamides or other drugs which yield the same colour in the analysis. The upper limits for acceptable $\mathrm{D} / \mathrm{C}$ concentration ratios, 150 $\mu \mathrm{g} / \mathrm{mg}$ for patients on DDS $100 \mathrm{mg} /$ day, $120 \mu \mathrm{g} / \mathrm{mg}$ for those on DDS 50 $\mathrm{mg} /$ day, were set slightly higher than the upper limits observed by Low and Pearson (1974) in a study of fully compliant patients.

A further 76 results were not included in the calculation of group compliance rates (Tables 1,2 and 3 ) either because the numbers were too small for valid estimates to be made or because no appropriate supervised group of patients was available for comparison. The excluded data consisted of 14 results from Mandalay General Hospital and 22, 18, 14 and 8 from Madaya, Patheingui, Amarapura and Maymyo townships, respectively.

\section{CALCULATION AND STATISTICAL EVALUATION}

Estimates of the proportions of DDS doses taken by different groups of patients (compliance rates) were derived as described by Ellard et al. $(1974 a)$. Individual urine samples found to have $\mathrm{D} / \mathrm{C}$ concentration ratios of $<6.8$ $\mu \mathrm{g} / \mathrm{mg}$, the highest figure obtained in control urine samples from volunteers not taking DDS, were classified as negative. Patients providing such samples were judged to be totally non-compliant. 


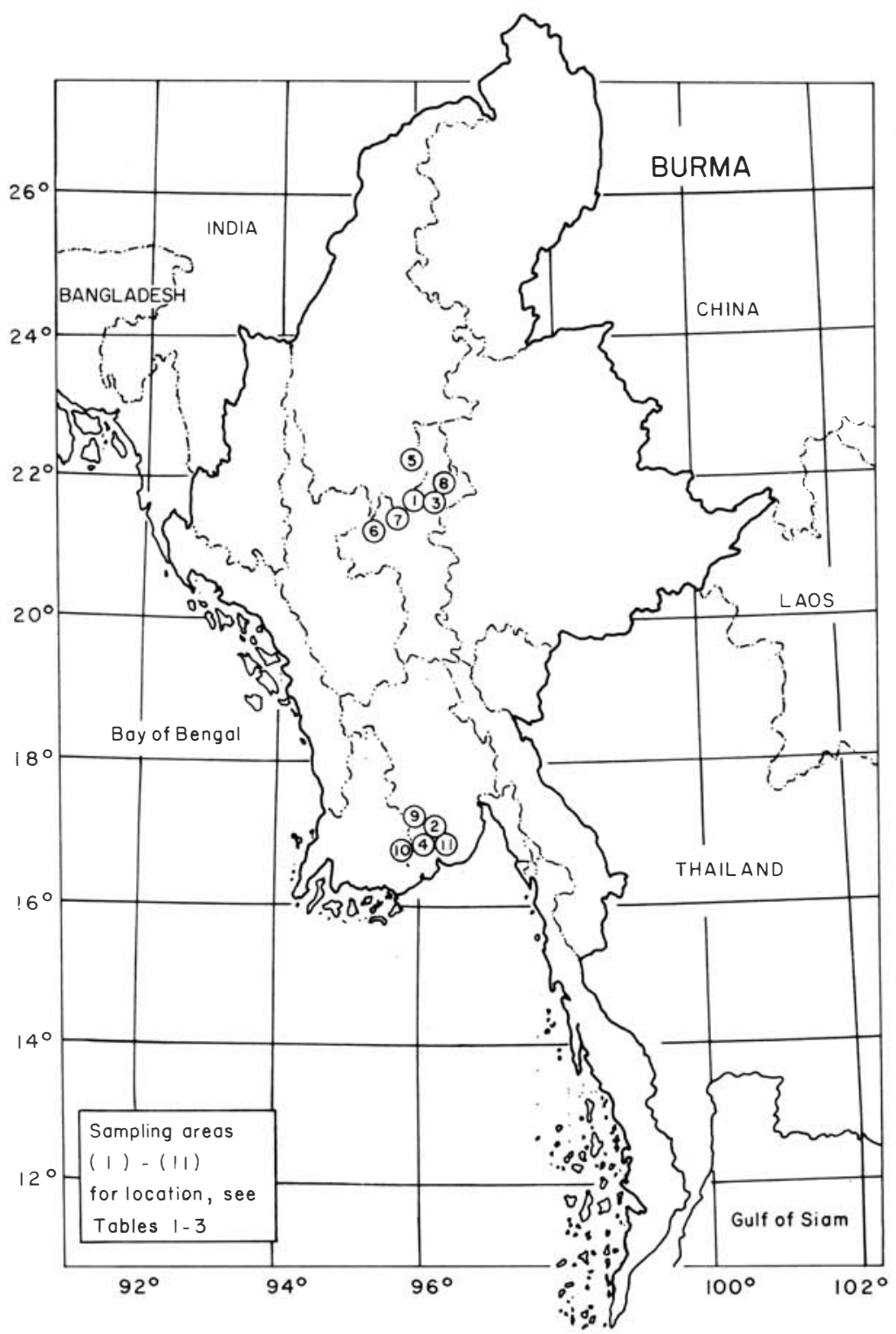

Fig. 1.

Comparisons between compliance and total non-compliance rates were effected by analysis of variance using a standard technique of nested data classification (Snedecor and Cochran, 1967). 


\section{Results}

Group means ( \pm S.E.M.) and ranges of individual D/C concentration ratios for in-patients, out-patients and urban and rural clinic patients are presented in Tables 1, 2 and 3 respectively. These tables also provide group estimates of percentages of DDS doses taken, together with sub-totals (by daily dosage) and weighted estimates of percentages of DDS doses taken (compliance rates) by each patient source (in-patients, out-patients, urban and rural clinic patients).

The results indicate that by comparison with in-patients (assumed compliance rates $100 \%$ ), out-patients and urban and rural clinic patients showed $74 \%$ and $24 \%$ compliance respectively. This difference was statistically highly significant $(P<0.001)$, but no significant difference was found in compliance rates between regions (Rangoon v. Mandalay) nor between dosages $(25,50$ or $100 \mathrm{mg} /$ day $)$ [Table $5(\mathrm{a})]$.

Estimates of the percentage of urine samples negative for DDS are given in Table 4. Seven per cent of in-patients, $24 \%$ of out-patients and $56 \%$ of urban and rural clinic patients had negative urines. The differences were statistically highly significant [Table 5(b)].

Group estimates of the percentage of DDS doses not taken (calculated from Tables 2 and 3) and the percentage of urines negative for DDS (calculated from Table 4), are illustrated in Fig. 2.

\section{Discussion}

This study has assessed the compliance with a 6 days/week DDS regimen in Burmese out-patients, by comparing the mean $\mathrm{D} / \mathrm{C}$ concentration ratios of patients fully compliant with DDS therapy with the values obtained from the out-patients. Fifty-three D/C concentration ratios $(6.2 \%)$ were excluded from the assessment because these ratios were unusually high. Several factors may have contributed to these high ratios:

(i) Simultaneous ingestion of sulphonamide therapy which may or may not have been officially prescribed. A similar problem was encountered by Ellard et al. (1974a), who were able to test suspect urine samples for interfering sulphonamides. Other drugs, notably the diuretics frusemide, hydrochlorothiazide, bendrofluazide and also diazepam and its metabolite desmethyldiazepam have also been found to interfere with the DDS assay in our laboratory. No interference was shown by rifampicin and its metabolites, clofazimine, erythromycin, indomethacin, clindamycin and its metabolite $\mathrm{N}$ demethylclindamycin, or pyrazinamide, when tested in the assay procedure. (ii) Patients ingesting more than the prescribed dose of DDS. It is conceivable that patient compliance was directly affected by the knowledge that they were to attend clinics (and temporary excess tablet consumption could result from this). The objective of this investigation was, however, kept hidden from patients, so the compliance study per se was unlikely to have influenced the results.

This study has shown substantial failure to comply with medication among some patients, most obviously those managed in urban and rural clinics. The 
TABLE 1

Mean D/C concentration ratios and estimates of percentage of prescribed DDS doses taken by each population: IN-PATIENTS AND CONTROLS

\begin{tabular}{|c|c|c|c|c|c|}
\hline \multirow{2}{*}{ Origin of samples (map ref.) } & \multirow{2}{*}{$\begin{array}{l}\text { No. of } \\
\text { subjects }\end{array}$} & \multirow{2}{*}{$\begin{array}{c}\text { Prescribed } \\
\text { DDS dosage } \\
(\mathrm{mg} / \text { day })\end{array}$} & \multicolumn{2}{|c|}{$\mathrm{D} / \mathrm{C}$ concentration ratio* } & \multirow{2}{*}{$\begin{array}{l}\text { Estimated \% } \\
\text { of doses taken }\end{array}$} \\
\hline & & & Mean \pm S.E.M. & Range & \\
\hline Leprosy Hospital, Mandalay (1) & 67 & 100 & $47.0 \pm 4.5$ & $5.0-150.5$ & 100 \\
\hline Leprosy Hospital, Mandalay & 15 & 50 & $38.3 \pm 7.5$ & $7.5-111.1$ & \\
\hline Htauk Kyant hospital (2) & 56 & 50 & $29.1 \pm 2.8$ & $4.0-89.5$ & \\
\hline (sub-total & 71 & 50 & $31.2 \pm 2.8$ & & 100) \\
\hline (estimated & - & 25 & 25.1 & & $100)$ \\
\hline ALL PATIENTS & 138 & $25-100$ & & & 100 \\
\hline VOLUNTEERS, no medication & 10 & 0 & $3.6 \pm 0.4$ & $2.0-6.8$ & \\
\hline
\end{tabular}

${ }^{*} \mu \mathrm{g}$ DDS/mg creatinine.

TABLE 2

Mean D/C concentration ratios and estimates of percentage of prescribed DDS doses taken by each population: OUT-PATIENTS

\begin{tabular}{lccccc}
\hline Origin of samples (map ref.) & $\begin{array}{c}\text { No. of } \\
\text { subjects }\end{array}$ & $\begin{array}{c}\text { Prescribed } \\
\text { DDS dosage } \\
\text { (mg/day) }\end{array}$ & $\begin{array}{c}\text { D/C concentration ratio* } \\
\text { Mean } \pm \text { S.E.M. }\end{array}$ & $\begin{array}{c}\text { Estimated } \% \\
\text { of doses taken }\end{array}$ \\
\hline Special skin clinic, & & & & & \\
$\quad$ Mandalay General Hospital (3) & 22 & 100 & $26.2 \pm 5.4$ & $0-120.0$ & 52 \\
Mandalay General Hospital & 24 & 25 & $17.3 \pm 3.5$ & $0-69.0$ & 64 \\
Mandalay General Hospital & 28 & 50 & $20.7 \pm 4.0$ & $0-66.7$ & 62 \\
Outpatient clinic & & & $31.6 \pm 4.3$ & $2.7-116.3$ & 100 \\
$\quad$ Rangoon General Hospital (4) & 45 & 50 & $23.1 \pm 2.9$ & $0.7-66.9$ & 71 \\
Htauk Kyant hospital (2) & 44 & 50 & & 80 \\
$\quad$ (sub-total & 117 & 50 & $25.8 \pm 2.2$ & & 74 \\
ALL PATIENTS & 163 & $25-100$ & & & \\
\hline
\end{tabular}

* $\mu \mathrm{g}$ DDS/mg creatinine. 
TABLE 3

Mean D/C concentration ratios and estimates of percentage of prescribed DDS doses taken by each population: URBAN \& RURAL CLINICS

\begin{tabular}{lccccc}
\hline Origin of samples (map ref.) & $\begin{array}{c}\text { No. of } \\
\text { subjects }\end{array}$ & $\begin{array}{c}\text { Prescribed } \\
\text { DDS dosage } \\
\text { (mg/day) }\end{array}$ & $\begin{array}{c}\text { D/C concentration ratio* } \\
\text { Mean } \pm \text { S.E.M. }\end{array}$ & $\begin{array}{c}\text { Range } \\
\text { of doses taken }\end{array}$ \\
\hline Htauk Kyant village (2) & 33 & 50 & $14.7 \pm 2.4$ & $2.1-59.7$ & 40 \\
Madaya township, Mandalay (5) & 58 & 50 & $14.7 \pm 2.7$ & $0.7-100.0$ & 40 \\
Patheingyi township, Mandalay (6) & 56 & 50 & $5.2 \pm 0.9$ & $0-37.0$ & 6 \\
Amarapura township, Mandalay (7) & 61 & 50 & $7.7 \pm 1.1$ & $0.4-44.0$ & 15 \\
Maymyo town, Mandalay (8) & 22 & 50 & $5.8 \pm 0.5$ & $0.9-16.6$ & 8 \\
(sub-total & 230 & 50 & $9.7 \pm 0.3$ & & $22)$ \\
Madaya township, Mandalay (5) & 38 & 100 & $6.8 \pm 1.5$ & $0.2-53.1$ & 7 \\
Taik Kyi area, Rangoon (9) & 59 & 100 & $21.9 \pm 3.3$ & $0-120.5$ & 42 \\
Hlegu area, Rangoon (10) & 47 & 100 & $14.7 \pm 2.6$ & $0-60.6$ & 26 \\
Hmawbi area, Rangoon (11) & 48 & 100 & $13.2 \pm 1.7$ & $0-56.8$ & 22 \\
(sub-total & 192 & 100 & $15.0 \pm 1.3$ & & $26)$ \\
ALL PATIENTS & 422 & $50-100$ & $12.1 \pm 0.5$ & & 24 \\
\hline
\end{tabular}

${ }^{*} \mu \mathrm{g} \mathrm{DDS} / \mathrm{mg}$ creatinine. 
TABLE 4

Estimate of urine samples negative for DDS (urine D/C concentration ratios $>6.8$ )

\begin{tabular}{|c|c|c|c|}
\hline Origin of samples (map ref.) & $\begin{array}{c}\text { No. of } \\
\text { subjects }\end{array}$ & $\begin{array}{c}\text { No. } \\
\text { negative }\end{array}$ & $\%$ \\
\hline \multicolumn{4}{|l|}{ IN-PATIENTS } \\
\hline Leprosy Hospital, Mandalay (1) & 82 & 4 & 5 \\
\hline Htauk Kyant hospital (2) & 56 & 5 & 9 \\
\hline ALL & 138 & 9 & 7 \\
\hline \multicolumn{4}{|l|}{ OUT-PATIENTS } \\
\hline Mandalay General Hospital (3) & 88 & 25 & 28 \\
\hline Rangoon General Hospital (4) & 45 & 8 & 18 \\
\hline Htauk Kyant (2) & 44 & 9 & 20 \\
\hline ALL & 177 & 42 & 24 \\
\hline \multicolumn{4}{|l|}{ URBAN AND RURAL CLINICS } \\
\hline Madaya township (5) & 118 & 62 & 53 \\
\hline Patheingyi township (6) & 74 & 58 & 78 \\
\hline Amarapura township (7) & 75 & 53 & 71 \\
\hline Maymyo township (8) & 30 & 20 & 67 \\
\hline Hlegu area $(10)$ & 47 & 26 & 55 \\
\hline Hmawbi area (11) & 48 & 19 & 40 \\
\hline Taik Kyi area (9) & 59 & 22 & 37 \\
\hline Htauk Kyant village (2) & 33 & 9 & 27 \\
\hline ALL & 484 & 269 & 56 \\
\hline
\end{tabular}

TABLE 5

Analyses of variance

\begin{tabular}{lcccc}
\hline Source of variation & $\begin{array}{c}\text { Sum of } \\
\text { squares }\end{array}$ & $\begin{array}{c}\text { Degrees of } \\
\text { freedom }\end{array}$ & Mean square & $F$
\end{tabular}

(a) \% DOSES TAKEN

\begin{tabular}{|c|c|c|c|c|c|}
\hline Between regions & 1162.88 & 1 & 1162.88 & \multirow{3}{*}{$\begin{array}{r}0.31 \\
61.21\end{array}$} & \multirow{3}{*}{$\begin{array}{c}\text { N.S. } \\
<0.001\end{array}$} \\
\hline Between sources within regions & 7397.36 & 2 & 3698.68 & & \\
\hline Between dosage within sources & 241.72 & 4 & 60.43 & & \\
\hline Within dosage & 1379.25 & 6 & $229.87\}$ & 0.26 & N.S. \\
\hline TOTAL & $10,181.21$ & 13 & & & \\
\hline \multicolumn{6}{|c|}{ \% URINES NEGATIVES FOR DDS } \\
\hline Between regions & 1411.87 & 1 & 1411.87 & \multirow{3}{*}{$\begin{array}{r}1.19 \\
11.29\end{array}$} & N.S. \\
\hline Between sources within regions & 4759.55 & 4 & 1189.89 & & \\
\hline Within sources & 737.50 & 7 & 105.36 & & $<0.01$ \\
\hline TOTAL & 6908.92 & 12 & & & \\
\hline
\end{tabular}




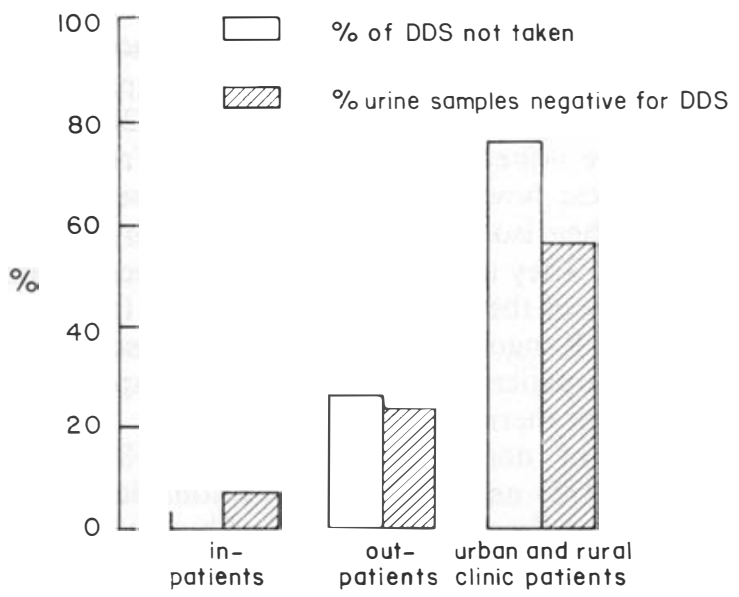

Fig. 2. Percentage estimates of non-compliance among different groups of leprosy patients.

results must, however, be interpreted with care. Leprosy patients attending out-patient departments in Mandalay and Rangoon weekly do not receive direct supervision of medication. Attendance at weekly intervals does, however, ensure continued motivation for compliance and continued supply of DDS tablets. The findings of an overall compliance rate of $74 \%$ and a totally non-compliant rate of $24 \%$ could be taken to indicate that a proportion of such patients are irregular attenders rather than poor tablet takers. This conclusion is supported by the observation that those urine samples which were positive for DDS contained on average as much drug as did the samples obtained from in-patients. By comparison, urban and rural clinic patients are not directly supervised at all. The estimates obtained in this group of $24 \%$ overall compliance and $56 \%$ total non-compliance are therefore likely to indicate more directly failure to adhere to the treatment regimen as such. In this case, for example, it is apparent that those patients who did comply took only half their tablets. In either instance, however, the findings show that there is substantial failure to take the drug in the absence of supervision. Such a conclusion warrants further discussion, as follows.

Because of the uncertainty of overlap in D/C concentration ratios between patients who are fully compliant and those not compliant with DDS therapy, no attempt was made to classify out-patients into those taking their doses regularly, irregularly or grossly irregularly (Ellard et al., 1974b). Instead urines were classified as either positive or negative, by the use of the highest $\mathrm{D} / \mathrm{C}$ concentration ratio in the blank values range. It is inevitable that some patients will be misclassified by this procedure and this is borne out by the finding that $5 \%$ of the in-patients from Mandalay and 9\% of those from Rangoon had negative urines. It is, however, also possible, although unlikely, that even supervised in-patients do not absolutely reliably receive their medication, some patients consistently evading it. 
The number of hospital out-patients found to have negative urines represents an unacceptable level of non-compliance. Those who attend hospital clinics are known to be well motivated to take their prescribed therapy and most are regular attenders. Even so, the finding that $24 \%$ of those attending the clinics had negative urines is of major concern. Urban and rural patients attending mobile clinics, however, present a more serious problem. These patients, by virtue of their isolation and life in a leprosy community, lack the motivation to be cured. They often fail to collect supplies of tablets, so it is not surprising to find many of them with negative urines. In the Taik Kyi, Hlegu and Hmawbi areas of Rangoon, the patients are prescribed higher doses of DDS than hospital out-patients in an attempt to compensate for the lack of motivation in taking their therapy.

The consequences of non-compliance with DDS therapy have been emphasized (Ellard, 1975) and it is clearly reasonable to conclude that the current prevalence of the disease in Burma (Tin Shwe, 1970) is at least partly a consequence of poor compliance among inadequately supervised patients. The practical solution appears to be to increase supervision with medication and our results support Ellard's suggestion that those patients who are relied upon to self-administer their DDS therapy require fully supervised intermittent therapy. This additional supervision could be given at clinic sessions with the proviso that those patients who default clinic attendances would be followed up.

This study has reinforced the idea that increased supervision with DDS therapy, both in hospital out-patients and urban and rural clinic patients in Burma, is urgently needed in order to reduce the prevalence of leprosy and the persistent emergence of new cases of this disease.

\section{Acknowledgements}

We are grateful to the World Health Organization for supplying the chemicals for this study and to the Government of the Union of Burma for permission to publish the findings. The analysis of the results was financed by grants from Ciba Laboratories and St Thomas' Hospital Endowments to whom we are greatly indebted.

\section{References}

Balakrishnan, S. (1977). Monitoring self-administration of dapsone by patients. Lepr. India 49, 364.

Bratton, A. C. and Marshall, E. K., Jr. (1939). A new coupling component for sulfanilamide determination. J. biol. Chem. 128, 537.

Ellard, G. A., Gammon, P. T., Helmy, H. S. and Rees, R. J. W. (1974a). Urine tests to monitor the self-administration of dapsone by leprosy patients. Amer. J. trop. Med. Hyg. 23, 464.

Ellard, G. A. Gammon, P. T. and Harris, J. M. (1974b). The application of urine tests to monitor the regularity of dapsone self-administration. Lepr. Rev. 45, 224.

Hagan, K. J. and Smith, S. E. (1979). Variability of urinary dapsone/creatinine concentration ratios in leprosy patients fully compliant with dapsone therapy. Lepr. Rev. 50, 129.

Huikeshoven, H. C. J., Honhoff, C., Van Eys, G. J. J. M., Anten, J. G. F., Mayer, J. M. A. and Van Helden, H. P. T. (1976). Weekly self-medication of leprosy patients monitored by DDS/creatinine ratios in urines. Lepr. Rev. 47, 201. 
Kin Ma Gyi, Maung Maung Lwin, Yi Yi Myaing, Khin Maw Oo and Tin Shwe (1978). Reliability of dapsone self-administration by leprosy patients in the Rangoon area. Lepr. Rev. 49, 283.

Low, S. J. M. and Pearson, J. M. H. (1974). Do leprosy patients take dapsone regularly? Le pr. Rev. 45, 218.

Naik, S. S. and Ganapati, R. (1977). Regularity of dapsone intake by leprosy patients attending urban treatment centre. Le pr. India, 49, 207.

Snedecor, G. W. and Cochran, W. G. (1967). Statistical Methods, 6th Edit., p. 285. Iowa State University Press, Ames.

Tin Shwe (1970). Leprosy in Burma. Lepr. Rev. 41, 121. 